\title{
EFFECT OF NICOTINE ON SPERMATOGENESIS IN ADULT ALBINO RAT
}

\author{
Wafik H. Nesseim, Heshmat S. Haroun, Mohamed E.A. Mostafa, \\ and Magdy F. Youakim \\ Anatomy Department, Faculty of Medicine, Cairo University
}

\section{INTRODUCTION}

Spermatogenesis is affected by many factors including smoking, as it causes fall in primary spermatocyte number, retardation of conversion of spermatocytes to spermatids in rats, as well as several morphologic abnormalities of sperms such as bicephalia (Kulikauskas et al., 1985).

Experimental evidence from humans and rodents suggested that nicotine, the most characteristic component of tobacco, could alter the hypothalamic-hypo-physeal axis through its stimulation of growth hormone, cortisol, vasopressin and oxytocin release which in turn inhibits the release of luteinizing hormone and prolactin (Weisberg, 1985).

Yeh et al. (1989) found that nicotine produced a dose-dependent decrease in androstenedione and testosterone concentrations in rats. Cotinine, a nicotine metabolite, produced a dose-dependent decrease in testosterone levels. Smokers had markedly reduced sperm volumes as compared with nonsmokers of the same age (Holzki et al., 1991).

Pekarsky et al. (1995) conducted a study to evaluate the effects of nicotine on the ability of human spermatozoa to be attached to and to penetrate the zona-free eggs and found that this ability was greatly affected by increase in nicotine concentrations. Reddy et al. (1995) noticed that nicotine significantly decreased sperm motion characteristics.

Yamamoto et al. (1998) observed a deficiency in spermatogenesis and sperm maturation in rats exposed to cigarette smokes. The authors also noticed that testosterone response to human chorionic gonadotropins (HCG) stimulation was significantly lower in rats exposed to nicotine. These findings suggested that smoking leads to a secretory dysfunction of the Leydig cells.

Zhang et al. (2000) found that the semen volume, the sperm density, viability and forward progression, as well as the seminal plasma contents of $\mathrm{Zn}$, $\mathrm{Cu}$ and superoxide dismutase (SOD) were much reduced in the medium, heavy and long-term smokers as compared to nonsmokers. 
Zitzmann et al. (2003) found that smoking decreased the success rates of assisted reproduction procedures such as in-vitro fertilization (IVF) and intracytoplasmic sperm injection (ICSI). Maternal smoking may have long-term implication on the reproductive health of the offsprings. Jensen et al. (2004) noticed that in-utero exposure to maternal smoking resulted in reduced both semen quality and testes size in adulthood.

However, all received literature failed to show the exact effect of increasing calculated doses of nicotine on spermatogenesis or to investigate possible recovery after its withdrawal.

The present work aims at detecting the possible effects of administration of calculated increasing doses of nicotine on spermatogenesis in the adult albino rats, the probable relationship between increasing the dose and/or duration of nicotine administration on spermatogenesis, and the possible structural recovery after nicotine withdrawal.

\section{MATERIAL AND METHODS}

Eighty-four adult male albino rats, aging three months and weighing 200-220 g, were used in this study.

The animals were housed in metallic cages of dimensions of $50 \times 30 \times 20 \mathrm{~cm}$ with wire mesh covers and were fed on ordinary laboratory diet with liberal supply of water.

\section{The animals were divided into the following groups:}

Group A consisted of 12 rats used as control, the animals received none of the injected substances.

Group B consisted of 12 rats used as sham control, the animals received a volume of saline equal to that of nicotine solution.

Group C consisted of 45 rats which were subdivided equally according to the dose of nicotine injected (Reddy et al., 1998) into:

Group $\mathrm{Cl}$ receiving $0.2 \mathrm{mg}$ nicotine $/ 100 \mathrm{~g}$ body weight / day.

Group Cll receiving $0.4 \mathrm{mg}$ nicotine / $100 \mathrm{~g}$ body weight / day.

Group CIII receiving $0.6 \mathrm{mg}$ nicotine / $100 \mathrm{~g}$ body weight / day. 
Each of the groups $\mathrm{Cl}$, II \& III was further subdivided, according to the duration of nicotine treatment, into the following subgroups:

Subgroup (a) received nicotine for two weeks.

Subgroup (b) received nicotine for four weeks.

Subgroup (c) received nicotine for eight weeks.

Group D consisted of 15 rats which received nicotine for eight weeks followed by nicotine-free duration for another eight weeks to assess testicular recovery. According to the dose of nicotine they received in the first eight weeks, they were subdivided into:

Group DI receiving $0.2 \mathrm{mg}$ nicotine / $100 \mathrm{~g}$ body weight / day.

Group DII receiving $0.4 \mathrm{mg}$ nicotine / $100 \mathrm{~g}$ body weight / day.

Group DIIl receiving $0.6 \mathrm{mg}$ nicotine / $100 \mathrm{~g}$ body weight / day.

Nicotine used in this study was in the form of vials of $25 \mathrm{ml}$ of nicotine $100 \%$, imported from Sigma, Germany. Nicotine was diluted in saline to obtain the required concentrations, and was then injected intra-peritoneally in the animals (Reddy et al., 1998).

Following the nominated periods, the rats were sacrificed by decapitation. Both testes of each animal were carefully dissected, removed, weighed and grossly examined for any abnormalities. The specimens were then fixed in Bouin solution, routinely processed for paraffin blocks and then transversely sectioned at $5 \mu \mathrm{m}$ thickness. The histological sections were stained with hematoxylin and eosin as well as Masson's trichrome stain and then examined by the light microscope.

Morphometric measurements of the diameters of the seminiferous tubules and spermatogenic cell count in the histological sections were carried out using Leica Qwin 500 image analyzer computer system. In each animal, the diameters of 100 transversely cut seminiferous tubules were measured. The spermatogenic cells were counted in $10 \mathrm{HPF}$ of each animal, and the mean value as well as the standard deviation were calculated by the computer system. Statistical analysis was done by using students " $t$ " test. 


\section{RESULTS}

\section{Macroscopical examination}

In the nicotine-injected rats, there was a progressive reduction in the mean values of the weight of the testes, when compared to those of the corresponding control and sham-control groups (Graph 1).

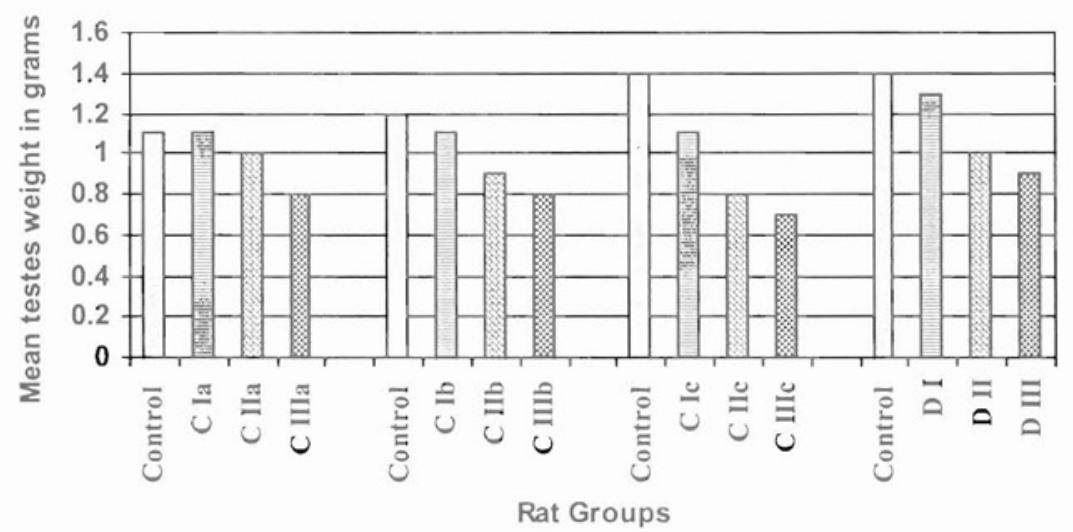

Graph (1): Bar chart showing the mean testes weight in various rat groups.

\section{Microscopical examination}

\section{Groups A \& B: Control and sham-control rats}

Examination of histological sections of the testes revealed normal architecture of seminiferous tubules. The spermatogenic cell masses were of average thickness and in close contact with the basal lamina. The seminiferous tubules showed Sertoli cells, spermatogonia, primary spermatocytes, spermatids and sperms. The interstitial cells of Leydig had rounded nuclei and eosinophilic cytoplasm (Figs. 1, 2).

\section{Group C: Nicotine injected rats}

Group Cl: Rats receiving $0.2 \mathrm{mg}$ nicotine:

After two weeks (group Cla) few seminiferous tubules showed mild degenerative changes in the form of slight reduction in the thickness of spermatogenic cell-mass and appearance of a clear space separating this mass from the basal lamina. Few Sertoli cells exhibited little vacuolation. Minimal exudate was observed between tubules (Figs. 3, 4). 
After four weeks (group $\mathrm{Clb}$ ) increased numbers of seminiferous tubules were affected in the form of mild distortion. Sertoli cells exhibited more vacuolation. Radial fragmentation and clear separation of cells from the basal laminae were observed (Fig. 5).

After eight weeks (group $\mathrm{Clc}$ ) degenerative changes in the testes were pronounced, as more tubules were affected, a line of cleavage between the spermatogonia and the primary spermatocytes was observed in some tubules. Basal laminae were disrupted. A striking observation, at this stage, was the appearance of multinucleated giant cells and residual bodies (Figs. 6, 7).

Group CII: Rats receiving $0.4 \mathrm{mg}$ nicotine:

After two weeks (group Clla) there were reduced thickness of the spermatogenic cell-mass in many seminiferous tubules, clear separation of this cell-mass from the thickened basal lamina and vacuolation of the Sertoli cells. Excessive exudate compressed the seminiferous tubules causing their distortion and segregated the interstitial cells of Leydig into small islands of celis (Figs. 8, 9).

After four weeks (group Cllb) some seminiferous tubules became markedly shrunken and distorted, and the spermatogenic cell-mass was more clearly separated from the basal laminae with cellular shedding-off into the tubular lumen. Interstitial tissue showed exudate and congested blood vessels (Fig. 10).

With the elapse of eight weeks (group Cllc) marked degeneration in seminiferous tubules was obvious that exhibited patchy diminution of the spermatogenic cell-masses entangled with the prominent processes of Sertoli cells. Multinucleated giant cells and inflammatory cells were observed (Figs. 11, 12).

Group CIII: Rats receiving $0.6 \mathrm{mg}$ nicotine:

After two weeks (group Clla) some degenerated tubules were almost devoid of spermatogenic cells. Exudate between the tubules was more evident (Fig. 13).

After four weeks (group Clllb) degenerated seminiferous tubules exhibited severe diminution of the thickness of the spermatogenic cells, entangled between processes of Sertoli cells, with complete absence of sperms. The basal lamina was thickened (Figs. 14, 15).

With the largest dose of nicotine-injection, $0.6 \mathrm{mg}$, for the longest experimental duration, eight weeks, (group CIIIc), most of the seminiferous tubules were affected. The tubules were markedly shrunken, extensively distorted and widely separated from each other with loss of their normal 
configuration. The spermatogenic cell-mass was markedly diminished and shed off into tubular lumen. Macrophages, identified by their large size and foamy cytoplasm, were observed inside some degenerated seminiferous tubules (Figs. 16, 17).

\section{Group D: Rats receiving 8 weeks nicotine injection followed by 8 weeks nicotine-free recovery period}

After $0.2 \mathrm{mg}$ nicotine injection, group DI, showed rather complete recovery of the seminiferous tubules, in the form of regular tubular outline, adherence of the spermatogenic cell-mass to the basal lamina of the tubules and narrowing of the interstitial spaces between the tubules (Fig. 18).

The testes of rats receiving $0.4 \mathrm{mg}$ nicotine injection, group DII, showed recovery of most seminiferous tubules with few degenerated ones. The extracellular space showed some exudate and congested blood vessels (Fig. 19).

Examination of testes after $0.6 \mathrm{mg}$ nicotine injection, group DIII, revealed minimal recovery as most seminiferous tubules were shrunken, degenerated, and surrounded with thick basal lamina (Figs. 20, 21).

\section{Histomorphometric results}

The mean values of seminiferous tubules diameter (Table 1; Graph 2) showed decrease in nicotine-injected group for two weeks (Cla, Clla \& $\mathrm{Cllla}$ ). This decrease was only significant $(\mathrm{P}<0.05)$ in group Cllla. After four weeks, the decrease was significant in groups Cllb \& Clllb. After eight weeks, the decrease was significant in all groups (Clc, Cllc \& Clllc). After nicotine withdrawal, sminiferous tubules diameter also showed a decrease in groups DI, DII \& DIII when compared to the corresponding sham-control groups. This decrease was only significant in group DIII.

The mean number of Sertoli cells showed an insignificant decrease in nicotine-injected group (group C), DII \& DIII groups when compared to the corresponding sham-control group, but there was no difference between sham-control and DI group (Table 2; Graphs 3-6).

The mean number of spermatogonia showed an insignificant increase in groups $\mathrm{Cla} \& \mathrm{Clla}$, an insignificant decrease in groups $\mathrm{Cllla}, \mathrm{Clb}, \mathrm{Cllb}$, Cllib, Clc, Cllc \& D, a significant $(P<0.05)$ decrease in group Clllc when compared to the corresponding sham-control group (Table 2; Graphs 3-6).

The mean number of primary spermatocytes decreased significantly in groups CIIIb, Cllc, Clllc \& DIII, decreased insignificantly in the other groups when compared to the corresponding sham-control group (Table 2; Graphs $3-6)$. 
The mean number of spermatids decreased insignificantly in groups $\mathrm{Cla}, \mathrm{Clla}, \mathrm{Clb}, \mathrm{Clc}, \mathrm{DI}$, decreased significantly in the other groups when compared to the corresponding sham-control group (Table 2; Graphs 3-6).

The mean number of sperms decreased insignificantly in groups $\mathrm{Cla}$, $\mathrm{Clb} \& \mathrm{DI}$, decreased significantly $(\mathrm{P}<0.05)$ in other groups, when compared to the corresponding sham-control group (Table 2; Graphs 3-6).

Table (1): Mean values of the diameter of the seminiferous tubules in various rat groups.

\begin{tabular}{|l|c|}
\hline \multicolumn{1}{|c|}{ Animal groups } & Mean \pm SD \\
\hline Control and Sham-control groups (after 2 weeks) & $273.2 \pm 68.3$ \\
\hline Nicotine-treated group C I a & $254.3 \pm 63.5$ \\
\hline Nicotine-treated group C II a & $227.1 \pm 47.6$ \\
\hline Nicotine-treated group C III a & $175.4 \pm 43.3$ \\
\hline Control and Sham-control groups (after 4 weeks) & $278.8 \pm 66.9$ \\
\hline Nicotine-treated group C I b & $224.2 \pm 52.5$ \\
\hline Nicotine-treated group C II b & $181.2 \pm 36.9$ \\
\hline Nicotine-treated group C III b & $150.5 \pm 34.3$ \\
\hline Control and Sham-control groups (after 8 weeks) & $285.2 \pm 57.1$ \\
\hline Nicotine-treated group C I c & $195.3 \pm 40.6$ \\
\hline Nicotine-treated group C II c & $154.1 \pm 37.2$ \\
\hline Nicotine-treated group C III c & $132.6 \pm 33.8$ \\
\hline Control and Sham-control groups (after 16 wecks) & $287.7 \pm 63.2$ \\
\hline Nicotine-withdrawal group D I & $268.1 \pm 61.6$ \\
\hline Nicotine-withdrawal group D II & $241.6 \pm 51.6$ \\
\hline Nicotine-withdrawal group D III & $192.6 \pm 46.4$ \\
\hline
\end{tabular}

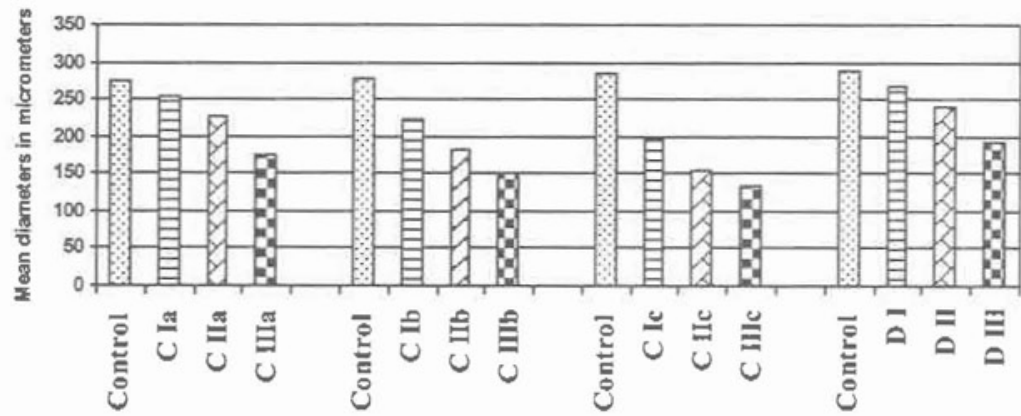

* Significant: $\mathrm{p}<0.05$.

Rat Groups

Graph (2): Mean values of the diameter of the seminiferous tubules in various rat groups. 
Table (2): Mean values of the number of Sertoli and spermatogenic cells in various rat groups.

\begin{tabular}{|c|c|c|c|c|c|}
\hline \multirow[t]{2}{*}{ Rat groups } & $\begin{array}{l}\text { Sertoli } \\
\text { cells }\end{array}$ & $\begin{array}{l}\text { Sperma: } \\
\text { togonia }\end{array}$ & $\begin{array}{c}1^{\text {ry }} \\
\text { sperma- } \\
\text { tocyte }\end{array}$ & $\begin{array}{l}\text { Spermat- } \\
\text { ids }\end{array}$ & Sperms \\
\hline & $\begin{array}{c}\text { Mean } \pm \\
\text { SD }\end{array}$ & $\begin{array}{l}\operatorname{Mean} \pm \\
\text { SD }\end{array}$ & $\begin{array}{l}\text { Mean } \pm \\
\text { SD }\end{array}$ & $\begin{array}{l}\text { Mean } \pm \\
\text { SD }\end{array}$ & $\begin{array}{l}\operatorname{Mean} \pm \\
\text { SD }\end{array}$ \\
\hline $\begin{array}{l}\text { Control and Sham- } \\
\text { control groups (after } 2 \\
\text { wecks) }\end{array}$ & $3 \pm 0.8$ & $5.7 \pm 0.9$ & $10.6 \pm 2.8$ & $17.7 \pm \overline{4.2}$ & $13.5 \pm 2.9$ \\
\hline $\begin{array}{l}\text { Nicotine-treated growp C } \\
\text { l a }\end{array}$ & $2.9 \pm 0.6$ & $5.9 \pm 1.2$ & $10.2 \pm 2.4$ & $15.9 \pm 3.2$ & $11.7 \pm 2.6$ \\
\hline $\begin{array}{l}\text { Nicotine-treated group C } \\
\text { II a }\end{array}$ & $2.5 \pm 0 . \overline{4}$ & $6 \pm 1.4$ & $8.6 \pm 1.9$ & $13.2 \pm 2.4$ & $7.4 \pm 1.9$ \\
\hline $\begin{array}{l}\text { Nicotine-treated group C } \\
\text { III a }\end{array}$ & $2.2 \pm 0.4$ & $5.6 \pm 0.7$ & $8.2 \pm 1.6$ & $9.5 \pm 2.1$ & $5.2 \pm 1.2$ \\
\hline $\begin{array}{l}\text { Control and Sham- } \\
\text { control groups (after } 4 \\
\text { weeks) }\end{array}$ & $2.8 \pm 0.7$ & $5.9 \pm 1.5$ & $11.4 \pm 2.6$ & $21.2 \pm \overline{4.7}$ & $17.4 \pm 3.4$ \\
\hline $\begin{array}{l}\text { Nicotine-treated group C } \\
\text { I b }\end{array}$ & $2.5 \pm 0.6$ & $5.7 \pm 1.2$ & $10.2 \pm 2.2$ & $1 \overline{7 \pm 3.4}$ & $13.3 \pm 3.1$ \\
\hline $\begin{array}{l}\text { Nicotine-treated group C } \\
\text { II b }\end{array}$ & $2.3 \pm 0.6$ & $5.5 \pm 1$ & $8.8 \pm 1.7$ & $12 \pm 2.5$ & $9.6 \pm \overline{1.8}$ \\
\hline $\begin{array}{l}\text { Nicotine-treated group C } \\
\text { III b }\end{array}$ & $1.9 \pm 0.4$ & $4.7 \pm 0.9$ & $6.4 \pm 1.4$ & $8.3 \pm 2.1$ & $6.4 \pm 1.6$ \\
\hline $\begin{array}{l}\text { Control and Sham- } \\
\text { control groups (after } 8 \\
\text { weeks) }\end{array}$ & $2.9 \pm 0.9$ & $7.1 \pm 2.2$ & $11.9 \pm 3.1$ & $25.6 \pm 4.6$ & $21.1 \pm 3.7$ \\
\hline $\begin{array}{l}\text { Nicotine-treated group C } \\
\text { l c }\end{array}$ & $2.6 \pm 0.8$ & $5.2 \pm 1.4$ & $7.4 \pm 1.6$ & $14.5 \pm 3.4$ & $10.6 \pm 2.3$ \\
\hline $\begin{array}{l}\text { Nicotine-treated group C } \\
\text { II c }\end{array}$ & $2.1 \pm 0.5$ & $4.2 \pm 1.1$ & $6.1 \pm 1.5$ & $10.8 \pm 3.1$ & $7.2 \pm 2.1$ \\
\hline $\begin{array}{l}\text { Nicotine-treated group } \bar{C} \\
\text { III c }\end{array}$ & $1.7 \pm 0.3$ & $3.5 \pm 0.9$ & $4.3 \pm 0.9$ & $5.1 \pm 1.3$ & $4.3 \pm 1.1$ \\
\hline $\begin{array}{l}\text { Control and Sham- } \\
\text { control groups (after } 16 \\
\text { weeks) }\end{array}$ & $2.7 \pm 0.8$ & $6.2 \pm 1.7$ & $12.6 \pm 2.8$ & $25.1 \pm 5.7$ & $23.4 \pm 4.6$ \\
\hline $\begin{array}{l}\text { Nicotine-withdrawal } \\
\text { group D I }\end{array}$ & $2.7 \pm 0.6$ & $5.9 \pm 1.4$ & $11.1 \pm 2.4$ & $22.3 \pm 3.8$ & $21.2 \pm 3.9$ \\
\hline $\begin{array}{l}\text { Nicotine-withdrawal } \\
\text { group DII }\end{array}$ & $2.4 \pm 0.7$ & $5.1 \neq 1.2$ & $8.1 \pm 1.6$ & $15.6 \pm 3.5$ & $12.4 \pm 3.1$ \\
\hline $\begin{array}{l}\text { Nicotine-withdrawal } \\
\text { group DIII }\end{array}$ & $2.2 \pm 0.6$ & $4.6 \pm 0.9$ & $6.5 \pm 1.2$ & $11.2 \pm 3$ & $8.8 \pm 1.6$ \\
\hline
\end{tabular}




\section{Graph (3)}

\begin{tabular}{|ll|}
\hline Sham-control group & $\boxminus$ nicotine-treated group C la \\
$\square$ Nicotine-treated group C Ila & Nicotine-treated group C Illa
\end{tabular}

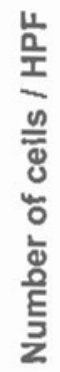

20

18

i 16

\& 12

○ 10

8
․․

2
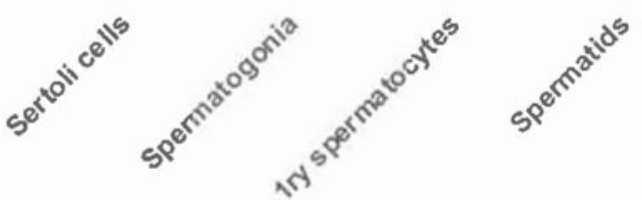

Type of cells

* Significant: $p<0.05$.

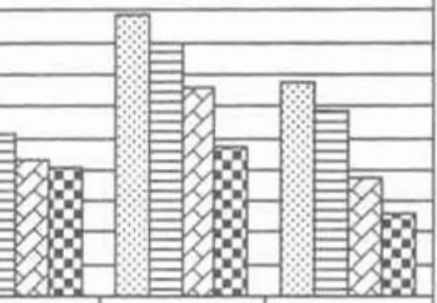

Graph (4)

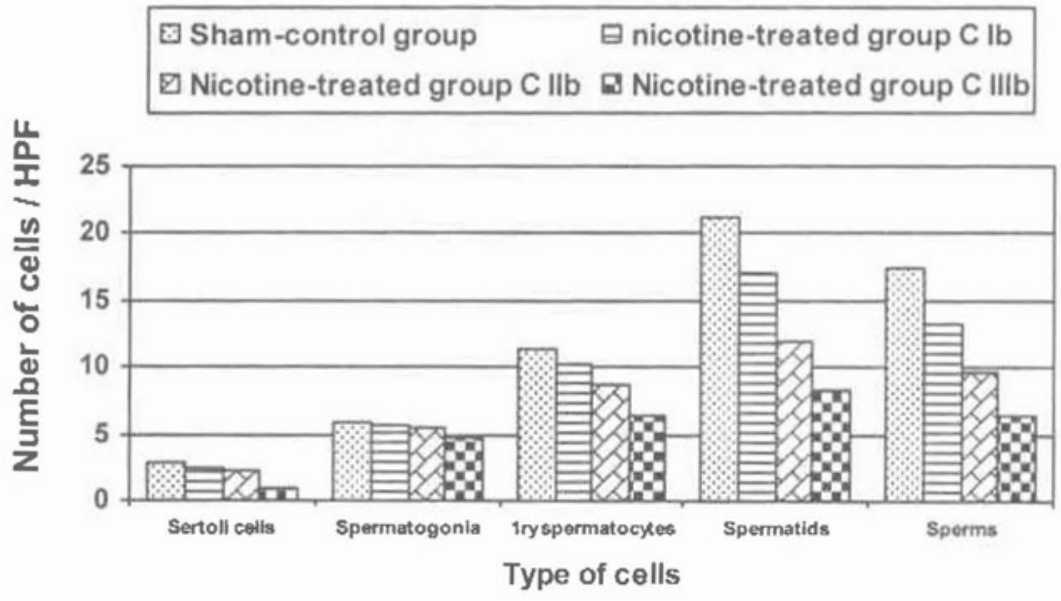

* Significant: $\mathrm{p}<0.05$. 
Graph (5)

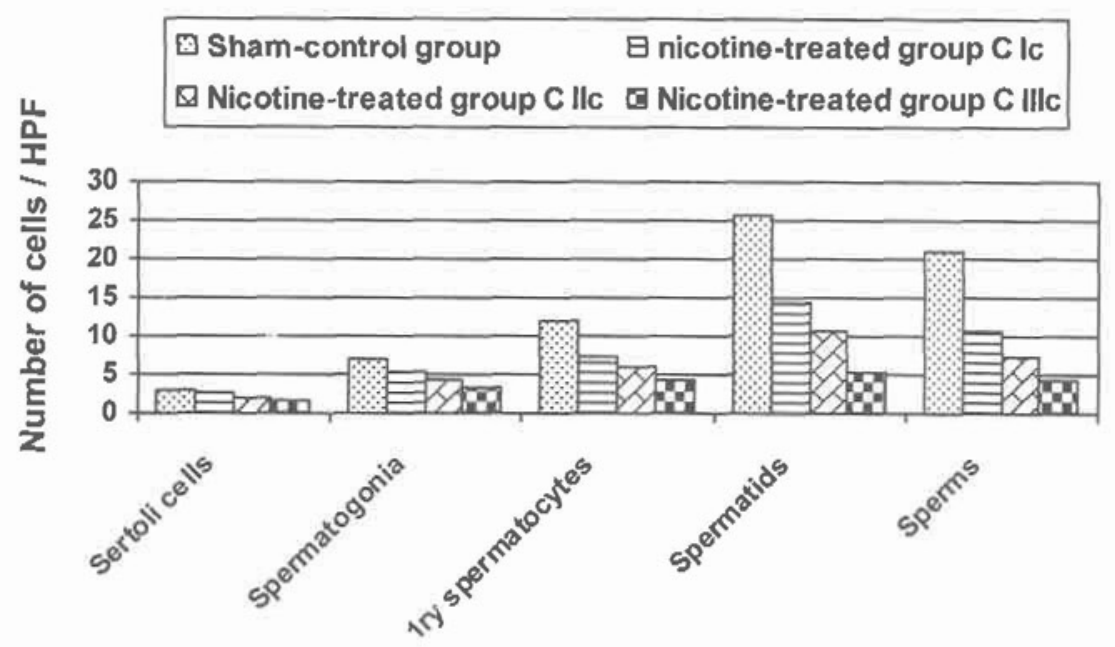

Type of cells

* Significant: $\mathrm{p}<0.05$

$$
\text { Graph (6) }
$$

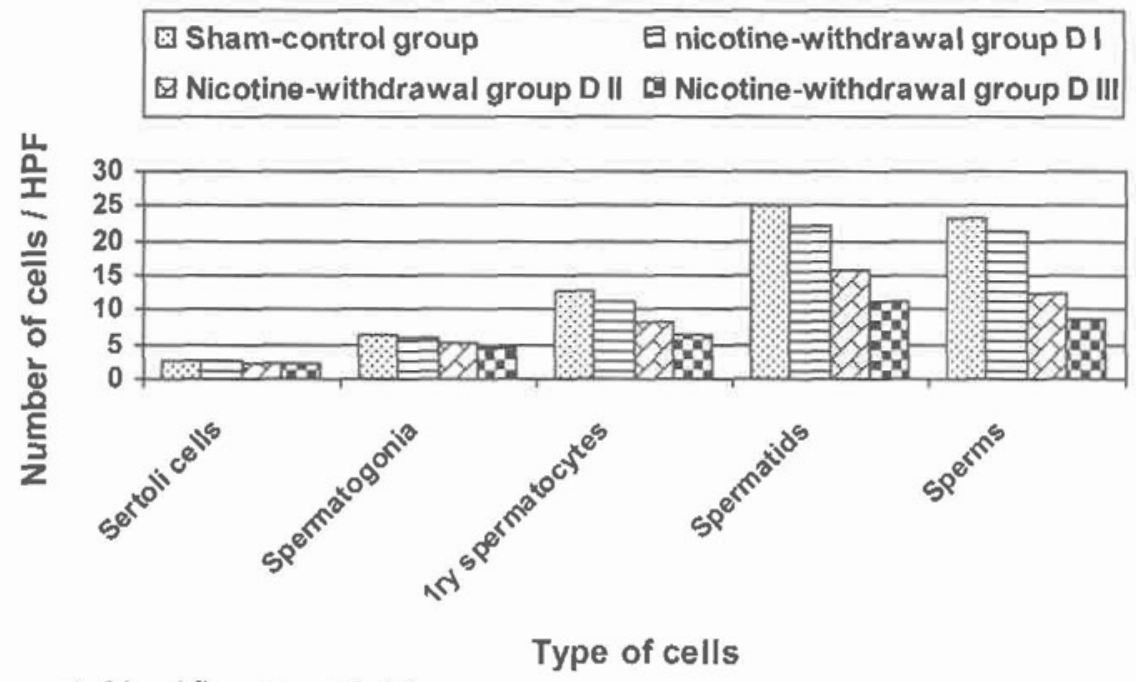

* Significant: $p<0.05$.

Graphs (3-6): Mean values of the number of Sertoli and spermatogenic cells in various rat groups. 


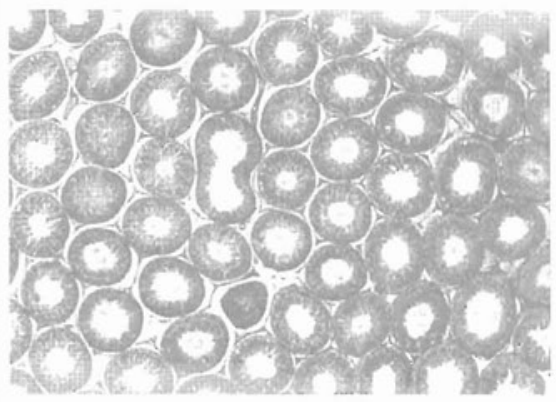

Fig. (1): A photomicrograph of a transverse section of the testis of a control rat (Group A) showing normal architecture of the seminiferous tubules. The spermatogenic cellmasses are of average thickness and in close contact with the basal lamina.

(H\& $E ; x 40)$

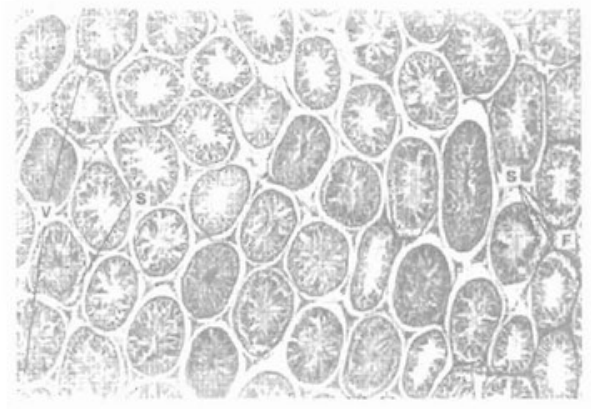

Fig. (3): A photomicrograph of a transverse section of the testis of an experimental rat receiving $0.2 \mathrm{mg}$ nicotine for 2 weeks (Group Cla) showing some mildly degenerated seminiferous tubules in the form of reduction of the thickness of the spermatogenic cell-masses and their separation from the basal lamina by clear space (S). Some Sertoli cells exhibit vacuolation (V) and the little fluid exudates is present $(F)$.

$$
\text { ( } H \& E ; x \text { 40) }
$$

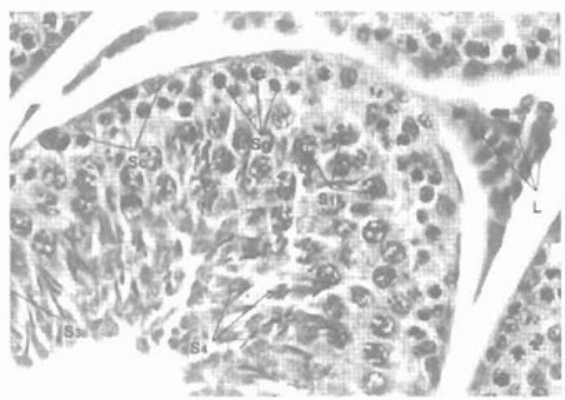

Fig. (2): Higher magnification of the section shown in Fig. (1) revealing healthy seminiferous tubules containing Sertoli cells $(\mathrm{Sc})$, spermatogonia $(\mathrm{Sg})$, primary spermatocytes (S1), spermatids (S3) and sperms (S4). The interstitial cells of Leydig $(L)$ have rounded nuclei and eosinophilic cytoplasm.

(H \& $E ; x$ 400)

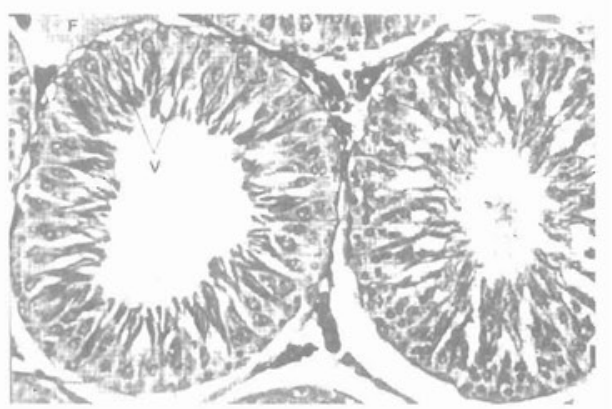

Fig. (4): A photomicrograph of a transverse section of the testis of an experimental rat receiving $0.2 \mathrm{mg}$ nicotine for 2 weeks (Group Cla) showing vacuolated Sertoli cells (V). fluid exudates $(F)$ is seen between some tubules.

(Masson trichrome; $\times 200$ ) 


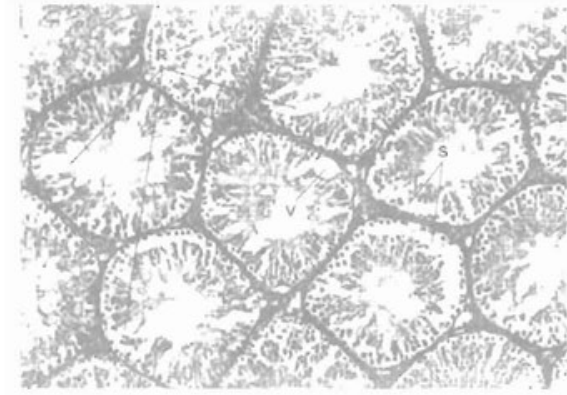

Fig. (5): A photomicrograph of a transverse section of the testis of an experimental rat receiving $0.2 \mathrm{mg}$ nicotine for 4 weeks (Group $\mathrm{Clb}$ ) showing mildly distorted seminiferous tubules, with vacuoles (V) in some Sertoli cells. The spermatogenic cell masses show radial fragmentation ( $R$ ) and are separated from the slightly thickened basal laminae by spaces (S).

(H \& E; x 100)

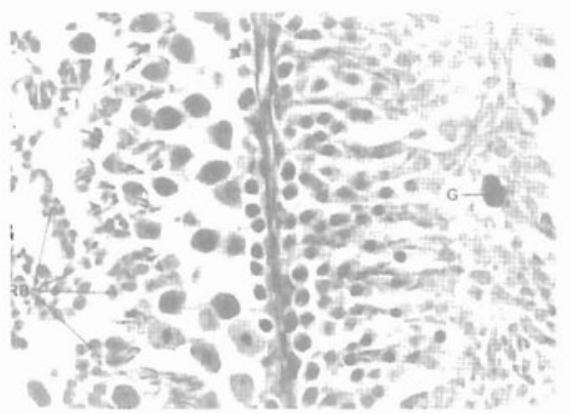

Fig. (7): A photomicrograph of a transverse section of the testis of an experimental rat receiving 0.2 mg nicotine for 8 weeks (Group $\mathrm{Clc}$ ) showing two adjacent seminiferous tubules separated by thick basal lamina and containing few spermatogenic cells. One tubule is filled with residual bodies (RB) and the other shows a multinucleated giant cell $(G)$.

$(H \& E ; x 400)$

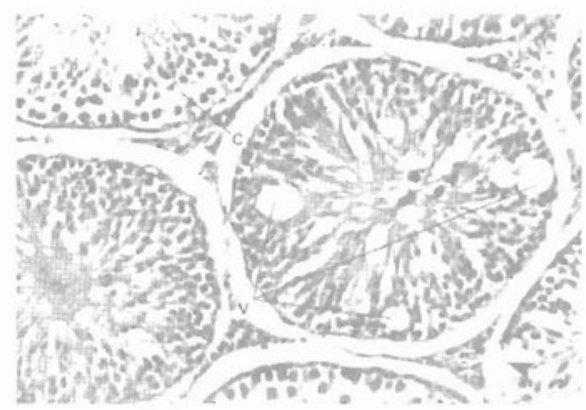

Fig. (6): A photomicrograph of a transverse section of the testis of an experimental rat receiving $0.2 \mathrm{mg}$ nicotine for 8 weeks (Group $\mathrm{Clc}$ ) showing vacuolated Sertoli cells (V). A line of cleavage $(C)$ is seen between spermatogonia and primary spermatocytes in one tubule and a disrupted basal lamina (arrow head) is seen in another tubule.

$(H \& E ; x 200)$

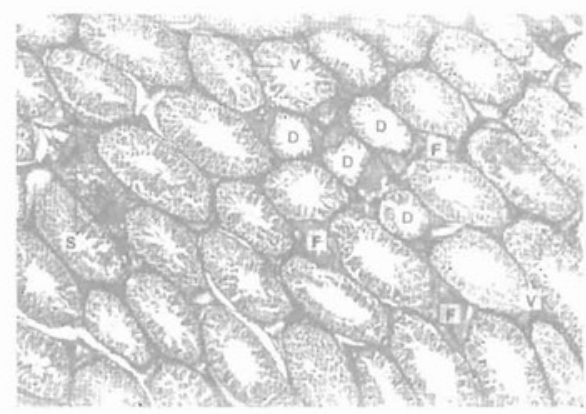

Fig. (8): A photomicrograph of a transverse section of the testis of an experimental rat receiving $0.4 \mathrm{mg}$ nicotine for 2 weeks (Group Clla) showing degenerated and distorted seminiferous tubules (D) that contain reduced spermatogenic cell-masses that are separated by a clear space (S) from the basal lamina. Sertoli cells exhibit vacuolation (V). The tubules are surrounded by an excess of fluid exudate $(F)$ compressing them.

$(H \& E ; x 40)$ 


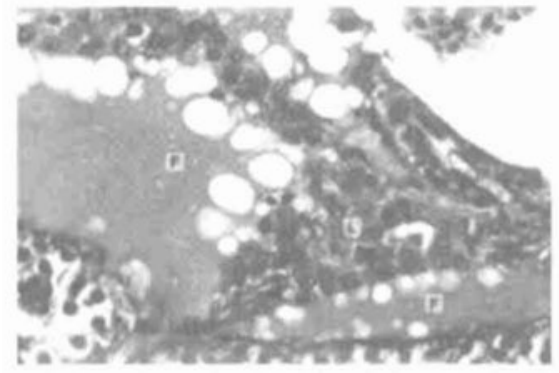

Fig. (9): Higher magnification of the section shown in Fig. (8) revealing islets of interstitial cells of Leydig (L) are isolated into cellular islands by an excess of vacuolated fluid exudate (F).

(H\& E; $x$ 400)

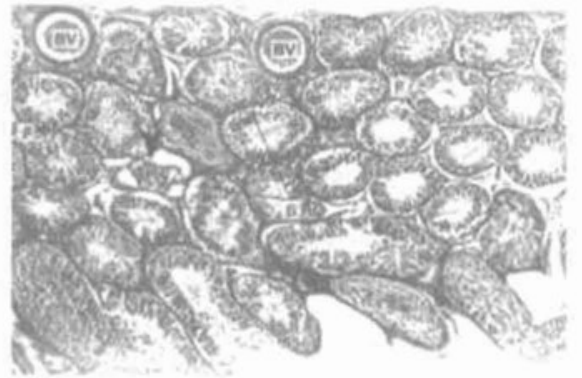

Fig. (10): A photomicrograph of a transverse section of the testis of an experimental rat injected by $0.4 \mathrm{mg}$ nicotine for 4 weeks (Group Cllb) showing a markedly shrunken and distorted seminiferous tubule (arrow head). Other tubules show degenerated spermatogenic cell-masses separated from basal laminae by clear spaces (S) and shed-off into the tubular lumina. Fluid exudate $(F)$ is present between the tubules and the blood vessels (BV) are congested.

$(H \& E ; x 40)$

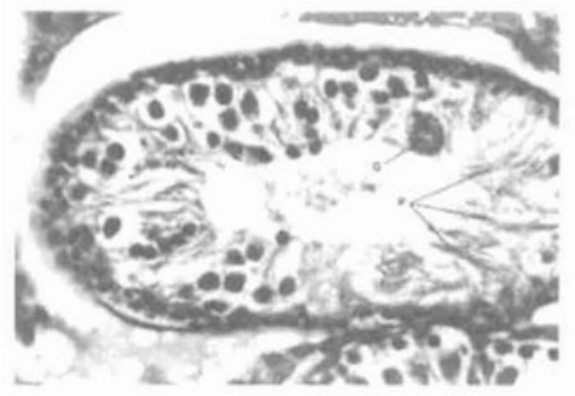

Fig. (11): A photomicrograph of a transverse section of the testis of an experimental rat receiving 0.4 $\mathrm{mg}$ nicotine for 8 weeks (Group Cllc) showing a markedly degenerated seminiferous tubule that exhibits patchy diminution of spermatogenic cells entangled by the prominent processes $(P)$ of Sertoli cells. A multinucleated giant cell $(G)$ is seen within the tubule.

$(H \& E ; x 400)$

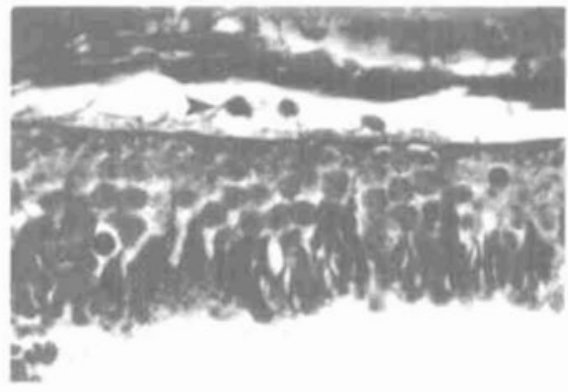

Fig. (12): A photomicrograph of a transverse section of the testis of an experimental rat receiving $0.4 \mathrm{mg}$ nicotine for 8 weeks (Group Cllc) showing lymphocytes (arrowheads) within and around the seminiferous tubules.

(Masson trichrome; $\times 1000)$ 


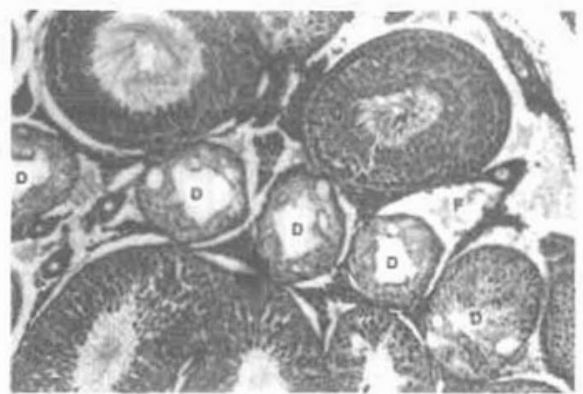

Fig. (13): A photomicrograph of a transverse section of the testis of an experimental rat receiving $0.6 \mathrm{mg}$ nicotine for 2 weeks (Group Cllla) revealing degenerated and shrunken seminiferous tubules (D) Between other less affected tubules. Fluid exudates $(F)$ is present between the tubules.

(H \& E; $x$ 100)

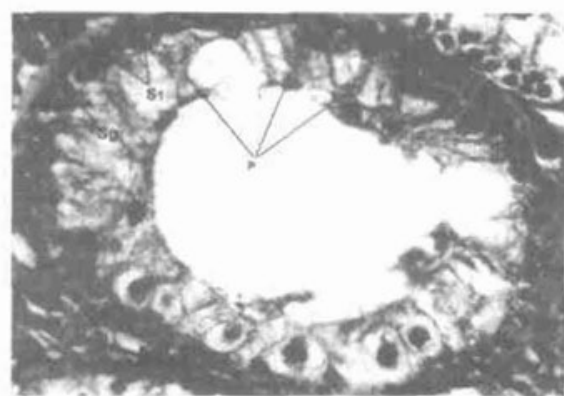

Fig. (14): A photomicrograph of a transverse section of the seminiferous tubule of an experimental rat receiving $0.6 \mathrm{mg}$ nicotine for 4 weeks (Group CIIlb) showing a markedly degenerated seminiferous tubule lined with few spermatogonia $(\mathrm{Sg})$ and primary spermatocytes (S1) entangled between processes $(P)$ of Sertoli cells, with complete absence of sperms. The basal lamina (arrow) is thickened.

$(H \& E ; x 400)$

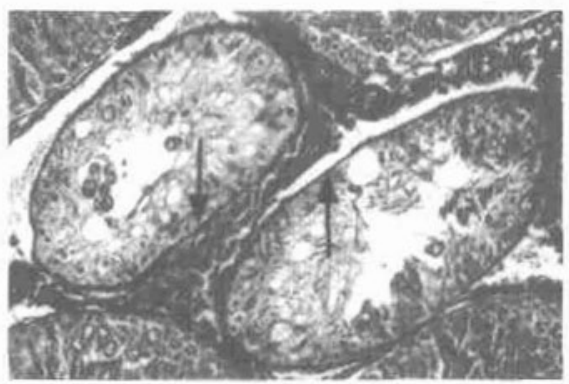

Fig. (15): A photomicrograph of a transverse section of the seminiferous tubule of an experimental rat receiving $0.6 \mathrm{mg}$ nicotine for 4 weeks (Group CIIlb) showing thickened basal laminae (arrows) around degenerated seminiferous tubules, reducing the spermatogenic cellmass.

(Masson trichrome; $\times 200$ )

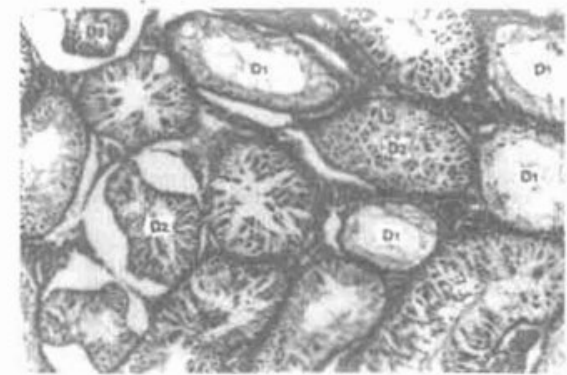

Fig. (16): A photomicrograph of a transverse section of the testis of an experimental rat receiving $0.6 \mathrm{mg}$ nicotine for 8 weeks (Group CIIIc) showing markedly shrunken, distorted and degenerated seminiferous tubules. The spermatogenic cellmasses are hugely diminished in some tubules (D1) while in others they are markedly shed off into the tubular lumina (D2).

$(H \& E ; x 100)$ 


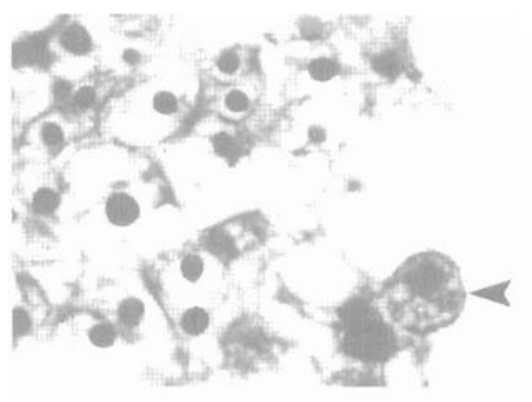

Fig. (17): A photomicrograph of a transverse section of the testis of an experimental rat receiving 0.6 $\mathrm{mg}$ nicotine for 8 weeks (Group CIIIc) showing few dispersed spermatogenic cells. A macrophage (arrowhead) is seen within the tubule.

$(H \& E ; x$ 1000)

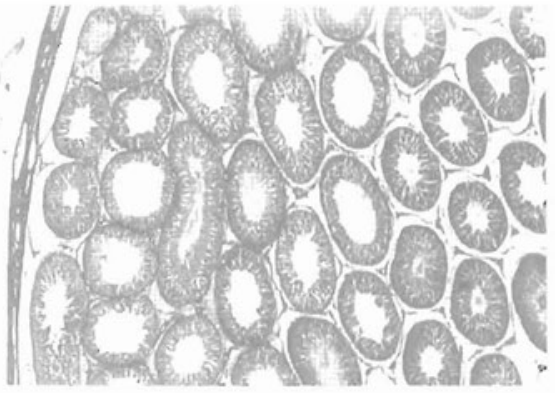

Fig. (18): A photomicrograph of a transverse section of the testis of an experimental rat after withdrawal of $0.2 \mathrm{mg}$ nicotine (Group DI) showing recovered seminiferous tubules in the form of regular tubular outline, adherence of spermatogenic cell-masses to the basal lamina and decreased interstitial spaces between the tubules.

$(H \& E ; x 40)$

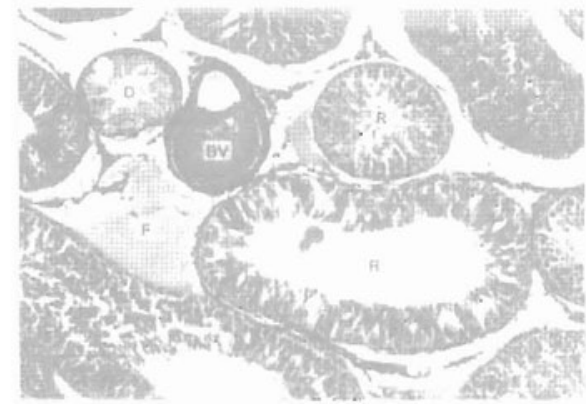

Fig. (19): A photomicrograph of a transverse section of the testis of an experimental rat after withdrawal of $0.4 \mathrm{mg}$ nicotine (Group DII) showing recovered seminiferous tubules (R) together with few still degenerated tubules (D). Some fluid exudate (F) is still present and the blood vessels (BV) are also still congested.

(H\& E; x 100)

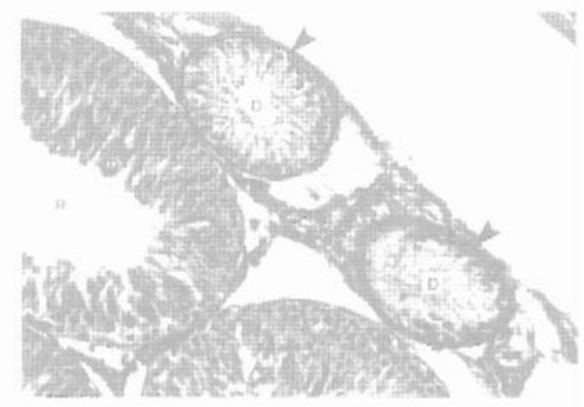

Fig. (20): A photomicrograph of a transverse section of the testis of an experimental rat after withdrawal of $0.6 \mathrm{mg}$ nicotine (Group DIII) showing recovered seminiferous tubules (R) adjacent to shrunken and degenerated tubules (D), surrounded with thickened basal lamina (arrowheads).

$(H \& E ; x 200)$ 


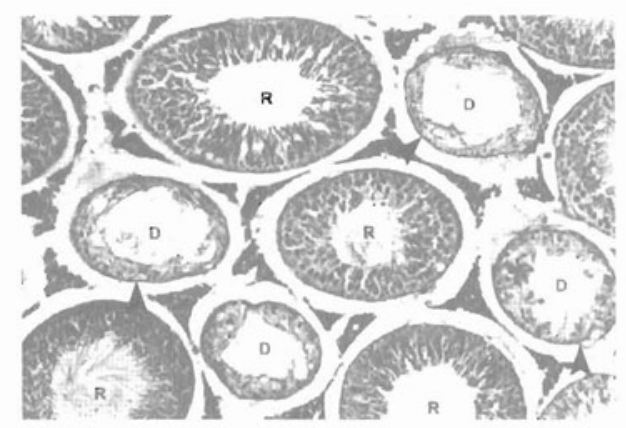

Fig. (21): A photomicrograph of a transverse section of the testis of an experimental rat after withdrawal of $0.6 \mathrm{mg}$ nicotine (Group DIII) showing recovered $(R)$ but still many degenerated (D) seminiferous tubules when compared to the previous stage. The basal lamina is still thickened.

(Masson trichrome; x 100)

\section{DISCUSSION}

The current study revealed that exposure to nicotine led to degenerative changes in the seminiferous tubules as shown by alteration of the general architecture of the seminiferous tubules and reduction in the number of the spermatogenic cells. These deleterious effects were directly proportional to the dose and duration of nicotine-adminitration. The smallest dose of nicotine $(0.2 \mathrm{mg} / 100 \mathrm{~g} \mathrm{BW} /$ day) for the shortest duration ( 2 weeks) did not induce any significant degenerative changes in the rat testes as compared to the control. With increased doses and durations of nicotinetreatment, the degenerative changes in the testes had increased. The largest dose of nicotine in this study $(0.6 \mathrm{mg} / 100 \mathrm{~g} \mathrm{BW} /$ day) for the longest duration ( 8 weeks) led to severe degenerative changes to the extent that some tubules appeared nearly devoid of spermatogenic cells. These results are in accordance with those observed by Reddy et al. (1998) who noticed a reduction in the number of spermatogenic cells (spermatogonia, spermatocytes and spermatids) after the administration of nicotine in albino rats. This cellular reduction was mentioned to be directly proportional to the dose of nicotine administered.

Moreover, Yamamoto et al. (1998), found a reduced sperm count and motility in the rats treated with nicotine. Furthermore, Zhang et al. (2000) and Künzle et al. (2003) noticed a reduction in sperm fertilizing capacity in smokers in addition to the decrease in sperm count and motility, Reduced sperm number observed by all of these authors, in man and rat, could be explained by the degenerative changes induced by nicotine in the testes of albino rats observed in the present work. 
An interesting finding in the current study is the late appearance of the multinucleated giant cells in the seminiferous tubules of rats injected with nicotine. The formation of these cells could be explained by the process of cell to cell fusion that occurs under pathological conditions as pointed out by Miething (1995) who described the detrimental effect of nicotine on testicular histology. This was also in accordance with the results of Holstein and Eckmann (1986) who referred to the appearance of multinucleated giant cells as an expression of germ cell degeneration.

The present work also revealed that the Sertoli cells were affected by nicotine-administration but to a lesser extent than did other spermatogenic cells. Sertoli cells showed reduction in their number and they appeared vacuolated. This vacuolation could be explained to be a result of degenerated spermatogenic cells that were phagocytosed by Sertoli cells giving rise to accumulation of lipid droplets and globules in their cytoplasm (Paniagua et al., 1991). The phagocytic capacity of Sertoli cells seemed to be lately impaired, in the present study, as revealed by the presence of excess residual bodies in the lumina of the seminiferous tubules. Such residual bodies released during spermatogenesis were normally phagocytosed by Sertoli cells (Somkuti et al., 1987). It is worth to be noted that the nicotine-affection of Sertoli cells, which are considered as the nurse of all germ cells (Griswold et al., 1988), probably resulted in more spermatogenic impairment. The current results support those of Aydos et al. (2001) who observed degenerated Sertoli cells that accumulated lipid droplets on exposure to nicotine. The authors concluded that nicotine might produce disturbance in Sertoli cell function that might affect spermatogenesis.

Another outstanding observation noticed in the present work, is that the seminiferous germinal epithelium was detached from the basal lamina and was seen sloughed inside the tubular lumina of the tubules in rats injected with nicotine. This could be attributed to the degeneration of germ cells together with the loss of the close contact between Sertoli and germ cells (Philips and Foster, 1985).

The thickening of the basal laminae of the seminiferous tubules observed in the present work could be attributed to fibrosis that could in turn contribute to the tubular compression and distortion. This finding is consistent with that of Aydos et al. (2001) who noticed a thickening caused by an increase in collagen fibers under the irregular basal laminae in the testes of rats exposed to nicotine. The authors also noticed more collagen fibers between the myoid cells surrounding the tubules.

The histopathological changes observed in this study and resulting from nicotine-administration might be explained by a dual mechanism: firstly, by a direct effect of nicotine on the testes and secondly by its indirect effect through interfering with hormones essential for spermatogenesis. 
Kavitharaj and Vijayammal (1999), reported that nicotine has a direct toxic effect on spermatogenic epithelium. Riesenfeld and Oliva (1988) reported that nicotine induces an inflammatory reaction in the testes, that directly contributes to testicular damage in rats injected with nicotine. Moreover, Saleh et al. (2002) also noticed that cigarette smoke is associated with an increase in the level of oxidants in the rat testes. The authors suggested that this abnormality of the oxidant-antioxidant balance might be one of the mechanisms leading to testicular damage and abnormal spermatogenesis in rats exposed to cigarette smoke. Zhang et al. (2000) found a significant decrease in superoxide dismutase in semen of smokers. Husain et al. (2001) and Rajpurkar et al. (2002) observed that nicotine administration caused depletion in glutathione, a well known anti-oxidant, in the testes of rats. The last two findings favor the importance of the oxidative damage induced by nicotine in the development of the testicular dystrophy.

Yeh et al. (1989) reported that nicotine inhibited multiple enzymes in testosterone biosynthesis. Sofikitis et al. (1995) reported secretory dysfunction of Leydig cells resulting in a lower testosterone level in smokers. The authors also reported a lower level of androgen-binding-protein secretion from Sertoli cells. The same findings were also reported by Yamamoto et al. (1998). Ochedalski et al. (1994) found that smokers have lower levels of $\mathrm{LH}, \mathrm{FSH}$ and prolactin hormones than nonsmokers. The authors suggested that these changes in the endocrine profile of smokers might lead to reduced fertility. Similarly, Weisberg (1985) mentioned that nicotine alters the hypothalamo-hypophyseal axis which in turn inhibits LH, FSH and prolactin release.

In the present work, the seminiferous tubules recovered after nicotine withdrawal. However, the degree of this recovery was variable depending on the dose of the nicotine injected. The present observations confirmed those of Meistrich (1986) who discovered regeneration of the germ cell population few weeks after cessation of nicotine. The current findings support those of Vine (1996) who observed an improvement of semen quality in smokers after quitting smoking. This author stated that men with marginal semen quality and wish to have children may benefit from quitting smoking. Recovery of the tubules after nicotine-withdrawal, observed herein, was demonstrated in the form of restoration of the thickness of the spermatogenic cell-masses, adherence of spermatogonia to the basal laminae, reduction of the vacuoles inside the Sertoli cells, and diminution of the residual bodies and sloughed cells inside the tubular lumina. However, the thickening of the basal laminae, the fluid exudate and the congestion of the blood vessels had not completely subsided. 
Accordingly, the triad of gross morphological, histological and histomorphometric findings described in this study may lead to the conclusion that smoking and particularly nicotine-exposure could adversely affect testicular integrity, spermatogenesis and in turn male fertility. These alterations in testicular function are nicotine dose- and time- dependent. Fortunately, such hazardous effects are almost reversible after nicotine withdrawal, especially in small doses. The current study recommends abstaining from smoking as it is highly injurious to male fertility as it is also well known to other body organs and systems. However, this work and its results should be extended on human specimens in further studies.

\section{SUMMARY}

Nicotine is a major constituent of tobacco-smoke and it adversely affects different systems of the body, including the male reproductive system.

To evaluate the deleterious effects of nicotine on spermatogenesis, eighty four mature male albino rats aging three months and weighing 200220 grams were utilized in this study. The animals were divided into four groups; group A (control), group B (sham-control), group C (nicotine treated), and group D (nicotine withdrawal). Group $\mathrm{C}$ was subdivided into $\mathrm{Cl}, \mathrm{Cll}, \mathrm{Clll}$ according to the dose of injected nicotine $(0.2,0.4$ and $0.6 \mathrm{mg}$ nicotine $/ 100 \mathrm{~g} \mathrm{BW/day}$ respectively). Furthermore each of these groups $\mathrm{Cl}$, CII, CIII was subdivided according to the duration of nicotine-treatment into subgroup "a" receiving nicotine for 2 weeks, subgroup "b" receiving nicotine for 4 weeks, subgroup " $c$ " receiving nicotine for 8 weeks. Group D which received nicotine for 8 weeks followed by nicotine-withdrawal for another 8 weeks to assess possibility of testicular recovery.

Transverse histological sections of the rat testes were stained with hematoxylin and eosin as well as Masson's trichrome stain and then examined by the light microscope. Morphometric measurements of the diameters of seminiferous tubules and spermatogenic cell count were determined using Leica Qwin 500 image analyzer computer system.

The present study has shown that exposure to nicotine leads to degenerative changes in the seminiferous tubules as revealed by alteration of the general tubular architecture, decrease in the thickness of the spermatogenic cell-masses, vacuolation of the Sertoli cells, reduction of spermatogenic cell-count, clearance of spermatogonia from the basal laminae, appearance of multinucleated giant cells and residual bodies and thickening of the basal laminae of the seminiferous tubules. The surrounding interstitial tissue was filled with fluid exudate and the blood vessels were congested. The degenerative changes in the seminiferous tubules were directly proportional to the dose and duration of nicotine-injection. 
Following nicotine-withdrawal, regeneration of the damaged seminiferous tubules was observed to be rather complete in the $0.2 \mathrm{mg}$ nicotinetreated group, with residual tubular damage in the $0.4 \mathrm{mg}$ and the $0.6 \mathrm{mg}$ nicotine-treated group. Recovery has been demonstrated in the form of restoration of the thickness of the spermatogenic cell-masses, adherence of spermatogonia to the basal laminae, reduction of vacuoles inside the Sertoli cells and diminution of the residual bodies and sloughed cells inside the tubular lumen and disappearance of multinucleated giant cells and inflammatory cells.

\section{REFERENCES}

1. Aydos, K.; Guven, M.C.; Can, B. and Ergun, A. (2001): Nicotine toxicity to the ultrastructure of the testis in rats. BJU Int., 88(6):622-626.

2. Griswold, M.D.; Morales, C. and Sylvester, S.R. (1988): Molecular biology of the Sertoli cell. Oxf. Rev. Reprod. Biol., 10:124-161.

3. Holstein, A.F. and Eckmann, C. (1986): Multinucleated spermatocytes and spermatids in human seminiferous tubules. Andrologia, 18:5-16.

4. Holzki, G.; Gall, H. and Hermann, J. (1991): Cigarette smoking and sperm quality. Andrologia, 23:141-144.

5. Husain, K.; Scott, B.R.; Reddy, S.K. and Somani, S.M. (2001): Chronic ethanol and nicotine interaction on rat tissue antioxidant defense system. Alcohol, 25:89-97.

6. Jensen,T.K.; Jorgensen, N.; Punab, M.; Haugen, T.B. and Suominen, J. (2004): Association of in utero exposure to maternal smoking with reduced semen quality and testis size in adulthood. Am. J. Epidemiol., 159:49-58.

7. Kavitharaj, N.K. and Vijayammal, P.L. (1999): Nicotine administration induced changes in the gonadal functions in male rats. Pharmacol., 58:2-7.

8. Kulikauskas, V.; Blaustein, D. and Ablin, R.J. (1985): Cigarette smoking and its possible effects on sperm. Fertil. Steril., 44:526-568.

9. Künzle, R.; Mueller, M.D.; Hänggi, W.; Birkhäuser, M.H.; Drescher, $\boldsymbol{H}$. and Bersinger, N.A. (2003): Semen quality of male smokers and nonsmokers in infertile couples. Fertil. Steril., 79:287-291.

10.Meistrich, M.L. (1986): Critical components of testicular function and sensivity to disruption. Biol. Reprod, 34:17-28. 
11.Miething, A. (1995): Multinuclearity of germ cells in the senescent human testis originates from a process of cell-cell fusion. J. Submicrosc. Cytol. Pathol., 27:105-113.

12.Ochedalski, T.; Lachowicz-Ochedalska, A.; Dec, $W$. and Czechowski, B. (1994): Examining the effects of tobacco smoking on levels of certain hormones in serum of young men. Ginekol. Pol., 65:8793.

13.Paniagua, R.; Nistal, M.; Sáez, F.J. and Fraile, B. (1991): Ultrastructure of the aging human testis. J. Electron Microsc. Tech., 19:241-260.

14.Pekarsky, A.; Rust, P.F.; Varn, E.; Mathur, R.S. and Mathur, S. (1995): Effects of nicotine on sperm attachment and penetration of zona-free hamster eggs. Arch. Androl., 34:77-82.

15.Philips, J. C. and Foster, P. M. (1985): Chemically induced injury to male reproductive tract. Toxicol. Appl. Phamacol., 95:484-489.

16.Rajpurkar, A.; Jiang, Y.; Dhabuwala, C.B.; Dunbar, J.C. and Li, H. (2002): Cigarette smoking induces apoptosis in rat testis. J. Environ. Pathol. Toxicol. Oncol., 21:243-248.

17.Reddy, A.; Sood, A.; Rust, P.F.; Busby, J.E.; Varn, E.; Mathur, R.S. and Mathur, S. (1995): The effect of nicotine on in vitro sperm motion characteristics. J. Assist. Reprod. Genet., 12:217-223.

18.Reddy, S.; Londonkar, R. and Pastil, S.B. (1998): Testicular changes due to graded doses of nicotine in albino mice, Indian J. Physiol. Pharmacol., 42: 276-280.

19.Riesenfeld, A. and Oliva, H. (1988): Effects of nicotine on the fertility, cytology and life span of male rats. Acta. Anat. (Basel), 131:171-176.

20.Saleh, R.A.; Agarwal, A.; Sharma, R.K.; Nelson, D.R. and Thomas, A.J. (2002): Effect of cigarette smoking on levels of seminal oxidative stress in infertile men: a prospective study. Fertil. Steril., 78:491. 499 .

21.Sofikitis, N.; Miyagawa, I.; Dimitriadis, D.; Zavos, P.; Sikka, S. and Hellstrom, W. (1995): Effects of smoking on testicular function, semen quality and sperm fertilizing capacity. J. Urol., 154:1030-1034.

22.Somkuti, S.G.; Lapadural, D.A.; Chapin, R.E.; Laub, J.C. and Abou Donia, M.B. (1987): Testicular toxicity following oral administration of trio-cresyl phosphate, TOCP in roosters. J. Toxicol. Lett. (Amst.), 37(3):
279-290. 
23.Vine, M.F. (1996): Smoking and male reproduction: a review. Int. J. Androl., 19:323-37.

24.Weisberg, E. (1985): Smoking and reproductive health. Clin. Reprod. Fertil, 3:175-186.

25.Yamamoto, Y.; Isoyama, E.; Sofikitis, N. and Miyagawa, I. (1998): Effects of smoking on testicular function and fertilizing potential in rats. Urol. Res., 26:45-48.

26.Yeh, J.; Barbieri, R.L. and Friedman, A.J. (1989): Nicotine and cotinine inhibit rat testis androgen biosynthesis in vitro. J. Steroid Biochem., 33:627-630.

27.Zhang, J.P.; Meng, Q.Y.; Wang, Q.; Zhang, L.J.; Mao, Y.L. and Sun, Z.X. (2000): Effect of smoking on semen quality of infertile men in Shandong, China. Asian J. Androl., 2:143-146.

28.Zitzmann, M.; Rolf, C.; Nordhoff, V.; Schräder, G. and RickertFöhring, M. (2003 ): Male smokers have a decreased success rate for in vitro fertilization and intracytoplasmic sperm injection. Fertil. Steril., 79(Suppl 3):1550-1554. 
الملخص الثربيى

تأثير النيكوتين على تكوين الحيوانات المنوية في الفأر الأبيض البالغ

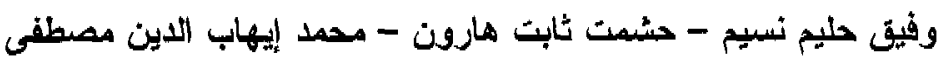

\section{- مجدي فؤاد يواقيم}

قسم التشريح - كلية الطب - جامعة القاهرة

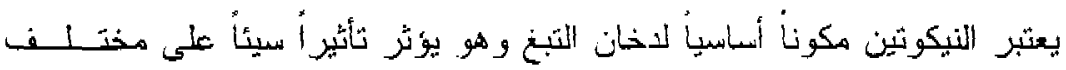

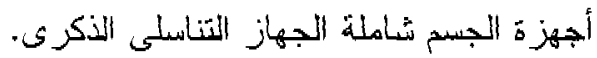

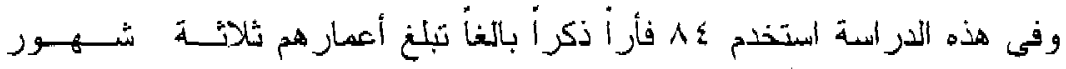

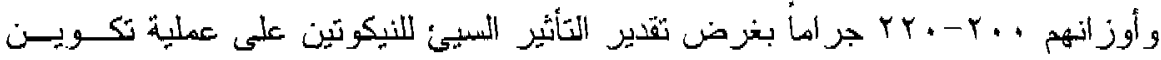

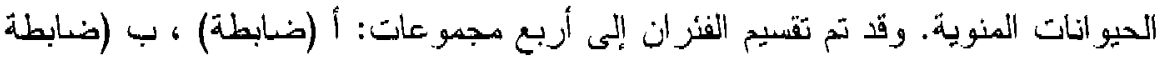

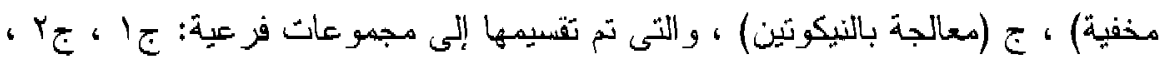

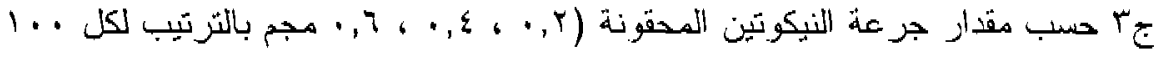

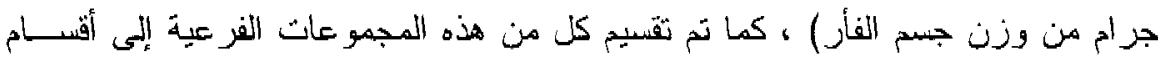

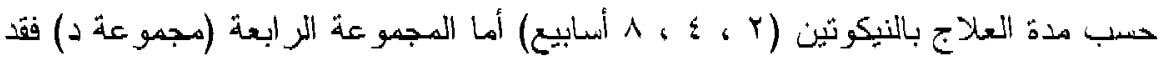

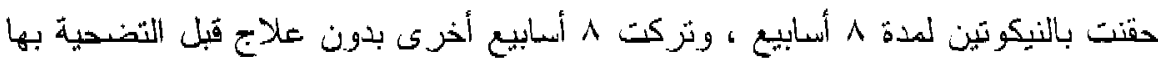

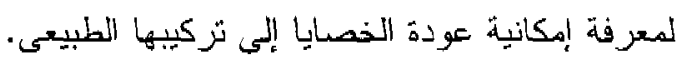

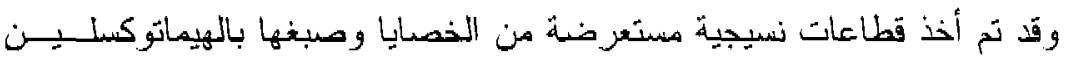

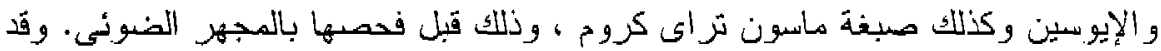

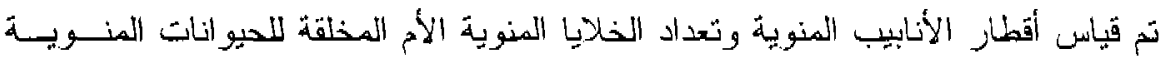

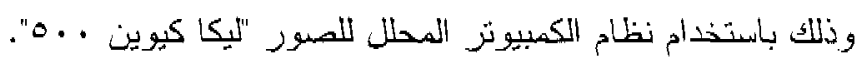

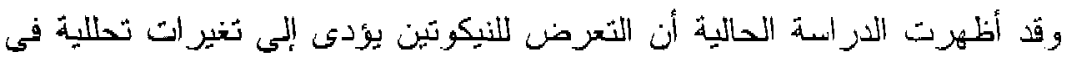

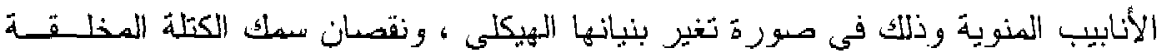

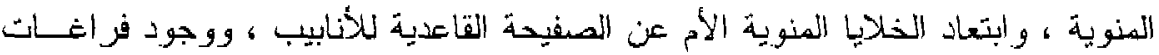

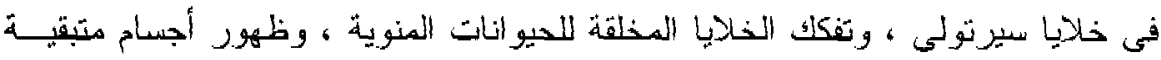

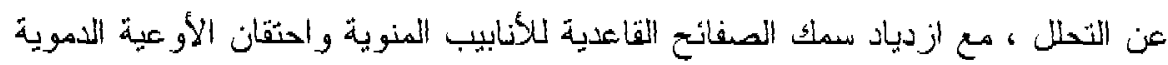

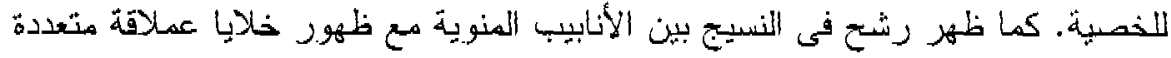

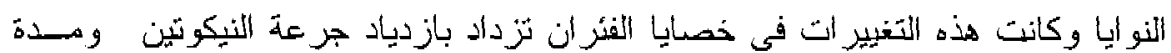

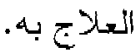


وبالامتتاع عن حقن النيكوتين لوحظ تجدد في الأنابيب المنوبية المتأثرة وكان هذا فئ

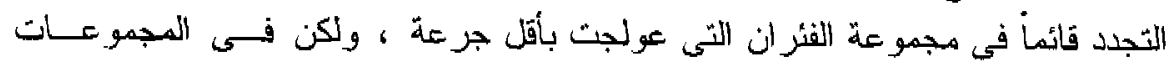

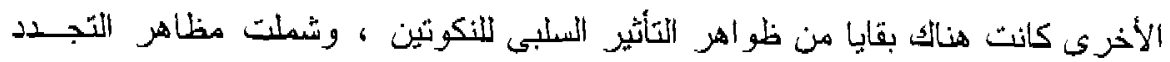

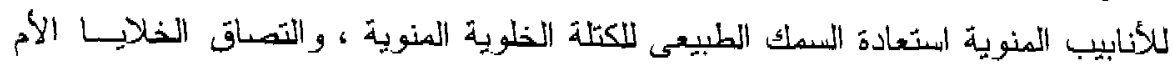

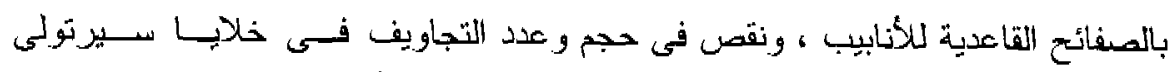

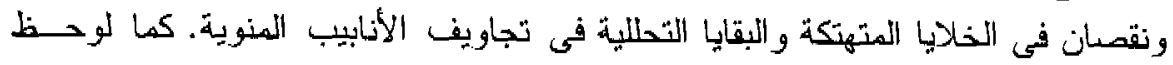
اختفاء الخلايا العهلاقة متعددة النو ايا و الخلايا الالتهابية.

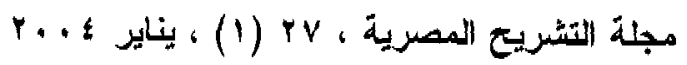

